\title{
The concept of organizing educational literary tourism by means of information technologies as a region development tool
}

\author{
Igor Kotciuba ${ }^{1}$, Alexey Shikov ${ }^{2}$, and Ruslan Vlasov ${ }^{3}$ \\ ${ }^{1}$ ITMO University, Kronverksky Av., 49, 197101 Saint Petersburg, Russia \\ ${ }^{2}$ Russian Academy of National Economy and Public Administration under the President of the \\ Russian Federation (North-West Institute of Management - a branch of RANEPA), Sredny prospect \\ V.O., 57/43, 199178 Saint Petersburg, Russia \\ ${ }^{3}$ Saint Petersburg State Technological Institute (Technical University), Moskovsky Av., 26, 190013 \\ Saint Petersburg, Russia
}

\begin{abstract}
The article discusses the development of the cultural potential of the region through the development of tourism. Educational tourism was chosen as one of the potentially attractive types of tourism, as well as its private direction - literary tourism, which has specificity in terms of methodological, organizational and communicational components. In the presented concept of organizing literary tourism, the development of an information system is described that allows one to fill the database with all the necessary information to implement the educational goals of literary tourism, taking into account the needs of users. Due to the ability to automatically retrieve the necessary information the designed and implemented information system significantly saves user's time and financial resources for organizing tourism, as well as automatically collects and stores data about the regional attractions found, which confirms the relevance of the study and the need to develop the described system, which has successfully passed testing and approbation. Prospects for further development imply a complete transition to web technologies in order to further popularize this information system among a large user audience of students and teachers both in megacities and in the regions.
\end{abstract}

\section{Introduction}

The most important area of the socio-economic development of the region is to involve society in this issue, including the popularization of the problems of cultural heritage in the educational sphere. This will solve several problems simultaneously: it will allow preserving old cultural sites by increasing the demand for them, expanding the list of objects visited by tourists including little-known and unknown previously, will form a new generation of people interested in preserving the culture of their region; partial commercialization will provide an inflow of funds to cultural and recreational facilities, contributing to their preservation and development.

Recently, tourism in Russia has been developing significantly due to the popularization of domestic direction and the significant economic effect of the industry both in 
megalopolises and in the regions. A significant number of local tourist sites became known to the general population and attracted attention to their preservation and dismantling thanks to informing about the socio-economic potential of Russian regions, as well as through the development of various strategies for organizing tourist decentralization and additional attraction of the flow of people to local cultural centers.

Among the various approaches to the classification of tourism according to the purpose of visit, one can single out the following categories of tourism activities related to sustainable development of territories:

1. Cultural tourism.

2. Rural tourism.

3. Event tourism.

4. Religious tourism.

5. Ecological tourism.

6. Educational tourism.

Thus, it can be concluded that the use of tourism in education is one of the areas of attracting society to the problems of region's socio-economic development. Nevertheless, the tourism implementation in the specifics of educational activities requires significant methodological study, which actualizes new research in this area.

The main implementation directions of educational tourism as a field of knowledge at the intersection of psychology, pedagogy and management are such functional components as:

1. Learning process management.

2. Organizational and communicative component management, based, inter alia, on the use of information technology in the field of tourism.

Thus, for the competent implementation of educational tourism, it is crucial to pay attention to the methodological, organizational and managerial support of this process, the main problems of the implementation of which in the field of education are:

1. Insufficient development of the theoretical base.

2. Insufficient degree of empirical achievements generalization.

3. Insufficient methodological study of the tourism and local history implementation.

4. Labor intensity of search work and research results fixation in a material format.

5. Weak plans for tourism activities development aimed at eliminating cultural and educational barriers.

6. Insufficient integration of the educational organizations' activities of with specialized travel agencies.

7. Lack of developed approaches to the tourist routes design, taking into account the educational specifics.

One of the directions of modern educational tourism development is one, that is specialized for the study of specific academic disciplines or related ones. An example of such an activity is literary tourism - the direction of cultural and educational tourism associated with the study of works of world classics, as well as the traditions of familiarization with regional literature.

The implementation of literary tourism has the following advantages in the framework of educational technology:

1. A deeper understanding of the relevance of the literary places' preservation [1].

2. An empirical assessment of the tourist's awareness of a literary work and the satisfaction degree with the location [2].

3. Rereading literary works based on personal experience, impressions and memories from trips.

4. Popularization of literary works as a source material before the start of tourist activities [3]. 
Within the framework of literary tourism, the user has the opportunity not only to get acquainted with the places of life and work of prominent literary figures, but also to pay attention to a wide range of related historical and cultural sites, such as museums, monuments, theaters, buildings, gardens and parks associated with the study of literary heritage, thereby immersing students in the socio-cultural environment in which the classics were born. As studies show [4], an increase in tourist attractiveness allows preserving archaic cultural objects due to an increase in demand for them, expands the list of objects by including little-known and previously unknown regional objects, forms a new generation of people interested in preserving the culture of their region; has a significant economic effect, allows marketing strategies [5], affects the minimization of a services package cost.

Most of the requirements currently associated with the development of information technology in tourism are associated with the search for methodological, algorithmic and software for the development of personalized tourist routes [6-8], which are diverse and realistic. However, tourists still have difficulties with the formation of a route affecting several destinations when integrating them in one trip, taking into account financial, timely and other constraints [9]. Significant predicaments exist with the calculation of time and distance for individual tourists and travel in groups, when the preferences and goals of group members may differ and conflict [10]. The business tourism is also interested in data analytics to distinguish the types of tourists based on the choice of places of their visit and traffic patterns [11]. In the works [3,5], the problems of planning literary tourism are considered, and it is also noted that keen readers prefer to plan their trips and avoid organized attractions, criticizing the methods of mass literary tourism.

Among the possible solutions to the above problems, mention should be made of the development of intelligent information systems that allow the large flow information analysis [9-12]. The use of intelligent systems makes it possible to combine user preferences [13] with effective automated methods for solving complex computational problems and provides a better understanding of the tourists' behavior for making better and faster decisions [6].

One of the solutions to the above problems is the development of a problem-oriented automated information system for organizing literary tourism in St. Petersburg, which would allow to quickly compose thematic routes based on data mining, as well as comprehensively study the heritage and biography of literary figures.

\section{Materials and methods}

The presented work relies on empirical research methods based on observation and research in the field of the literary educational tourism implementation by means of information technology. Studies [14] present a list of basic informational entities that are associated with literary tourism. For the system being developed, they can be used as entities stored in a database, with the ability to expand and add new categories:

1. Information about the socio-cultural environment with a description of the historical, cultural, every day, educational value.

2. Information about typology according to educational value.

3. Information about the diversity of traditions and customs of the sociocultural environment.

4. Information about the priority of visiting the sight, the possibility of its dynamic nature due to the change in the relevance of its visit by the society.

5. Information about the components of the natural and built environment in terms of their historical and aesthetic appeal.

6. Information about literary works, as well as audio, video information and photographs of sites. 
7. Information about guides and maps, distances between points of routes.

8. Expert information from experienced teachers in the field of organizing educational tours regarding the methodological and logistic areas.

Based on the analysis of the subject area and a review of similar solutions, the general functionality of the developed information system was formed:

1. Availability of a unified database containing the necessary information about authors, films, performances, works and locations;

2. Search for objects by author with the ability to filter;

3. Viewing the list of authors with the ability to search;

4. Viewing the biography of the author;

5. Watching movies about the author;

6. Viewing works of authors with allocation of places in St. Petersburg, mentioned in them;

7. Viewing the list of performances based on the works of the author or his biography

8. User registration;

9. User authorization;

10. Ability to comment and evaluate database objects;

11. Ability to search for places by authors and topics;

12. Route development;

13. Route editing;

14. Downloading the route for offline access.

Figure 1 shows the approbation results of the developed information system on specific examples of literary tourism:

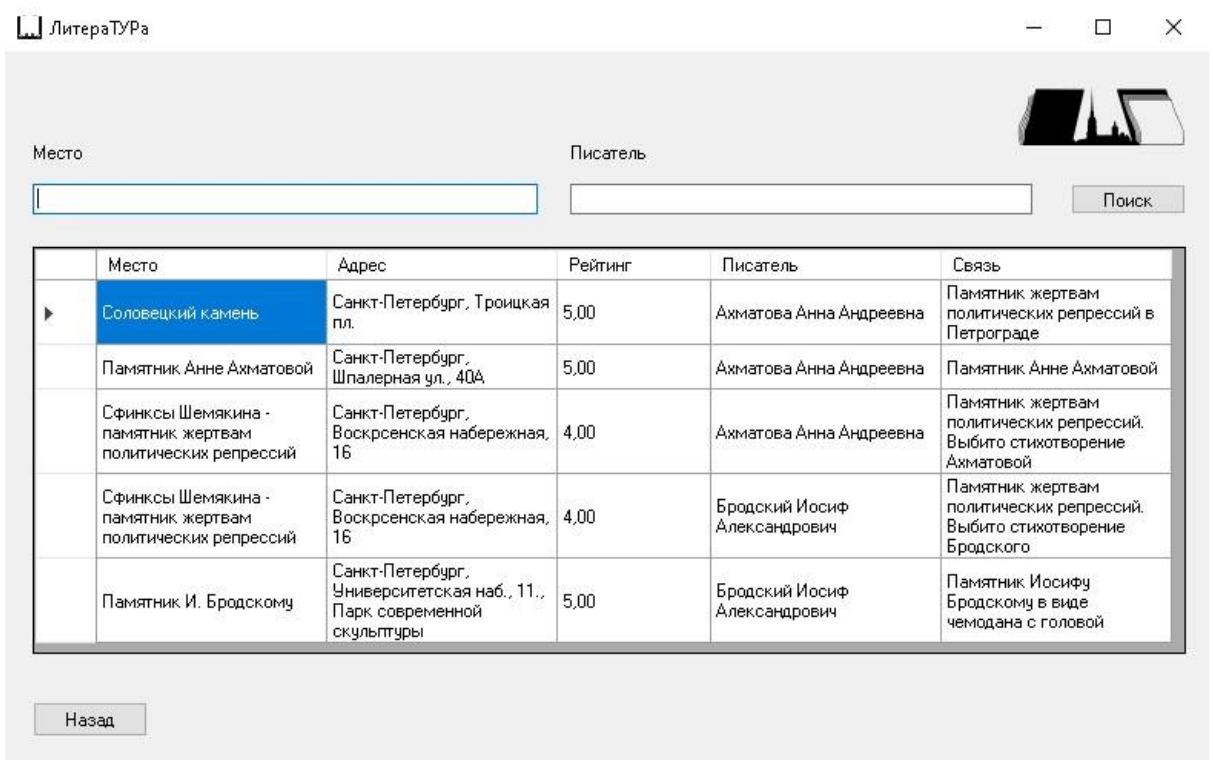

Fig. 1. Locations' worklist window

\section{Results}

At the current stage, a desktop application has been developed that allows filling the database with the entire list of information necessary for the implementation of literary tourism, as well as taking into account the needs of users. The developed software was tested in the framework of the educational work organization with students of the Faculty 
of Secondary Professional Education of ITMO University in the category of educational tourism. Empirical studies have proven the pedagogical effectiveness of the developed information technology for both the student and the teacher.

Students were able to automatically build individual routes; carry out an automatic search for works with navigation by authors of interest, literary directions; achieved greater immersion in the educational material through visualization and direct contact with the objects of literary study. Teachers noted the ability to automatically track both the literary interests of students and logistic preferences (travel options, infrastructure requirements), the most interesting tourist sites for students (museums, parks, monuments, places from the author's biography or heritage, etc.). From the point of view of organizing the didactics of the educational process, the teachers appreciated the opportunity to design tourism activities both in relation to the work program of the discipline, and within the framework of extracurricular reading and educational work; to organize a complex of tourist events for logically related or competing literary movements that need to be studied in combination (for example, symbolism and acmeism, formed as a reaction to the extremes of symbolism; baroque and its antipode classicism). From the point of view of the organizational and communicative component, the teachers noted a significant reduction in time and economic costs for the preparation and organization of tourist events due to the centralized storage of all content in various literary directions and the construction of the shortest routes to reach tourist sites.

\section{Conclusions}

Thus, the automation of the routes compilation of literary tourism allows one to significantly save time and makes it a possible means for solving the problem of attracting students of educational organizations to the cultural and recreational facilities of the region, and hence the socio-economic development of the region as a whole.

\section{References}

1. B. Canavan, Annals of Tourism Research, 78 (2019)

2. D. Herbert, Annals of Tourism Research, 28 (2001)

3. N. MacLeod, J. Shelley, A.M. Morrison, Tourism Management, 67 (2018)

4. S.J. Squire, Annals of Tourism Research, 21 (1994)

5. A. Hoppen, L. Brown, A. Fyall, Journal of Destination Marketing and Management, 3 (2014)

6. I. Cenamor, T. de la Rosa, S. Núñez, D. Borrajo, Expert Systems with Applications, 69 (2017)

7. W. Zheng, H. Ji, C. Lin, W. Wang, B. Yu, Tourism Management, 76 (2020)

8. C. Bassano, S. Barile, P. Piciocchi, J.C. Spohrer, F. Iandolo, R. Fisk, Cities, 87 (2019)

9. M.A. Uwaisy, Z.K.A. Baizal, M.Y. Reditya, Procedia Computer Science, 157 (2019)

10. W. Zheng, Z. Liao, Tourism Management, 72 (2019)

11. S. Ma, A.P. Kirilenko, S. Stepchenkova, Tourism Management, 77 (2020)

12. M. Sumardi, R. Wongso, F.A. Luwinda, Procedia Computer Science, 116 (2017)

13. O. Boulaalam, B. Aghoutane, D. El Ouadghiri, A. Moumen, M. Malinine, Procedia Computer Science, 134 (2018)

14. C. Fawcett, P. Cormack, Annals of Tourism Research, 28 (2001) 